\title{
Técnicas para el estudio anatómico del cerebro: una revisión
}

\section{Techniques for an Anatomic Approach to the Study of the Brain: A Review}

Recibido: 12/05/2020 | Aceptado: 19/06/2020

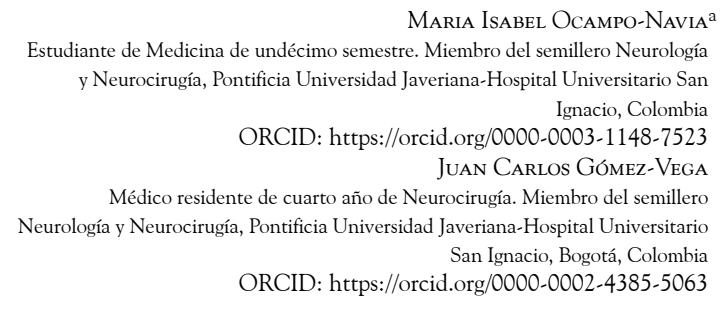

${ }^{a}$ Autora de correspondencia: mariaocampo97@gmail.com

Cómo citar: Ocampo-Navia MI, Gómez-Vega JC. Técnicas para el estudio anatómico del cerebro: una revisión. Univ. Med. 2021;62(1). https://doi.org/10.1 1144/Javeriana.umed62-1.teac

\section{RESUMEN}

Un entendimiento preciso de la anatomía cerebral es fundamental en la práctica y entrenamiento de los neurocirujanos. El estudio anatómico en cadáveres se ha convertido en uno de los métodos más útiles dentro de este campo, debido a que permite analizar variaciones anatómicas en poblaciones y entrenar habilidades quirúrgicas (técnica, profundidad y visoespacialidad), por medio de las disecciones para el mejor entendimiento de la anatomía humana y del sistema nervioso central. Por ello, las técnicas de preservación y coloración del tejido cerebral surgen como una alternativa para la educación morfológica, el entrenamiento y el aprendizaje de los residentes de neurocirugía. Esta revisión pretende describir estas técnicas y los diferentes métodos de coloración vascular cerebral. Con esto, buscamos facilitar la creación de laboratorios de microcirugía y proponer nuevas alternativas que pueden aplicarse en la educación de estudiantes y residentes de neurocirugía.

Palabras clave

cerebro; cadáver; neuroanatomía; disección; plastinación.

\section{ABSTRACT}

A precise understanding of cerebral anatomy is fundamental in the practice and training of neurosurgeons. The anatomic study of cadaveric specimens has become one of the most useful methods of education in this field, since it facilitates the study of anatomic variations in different populations and refines critical surgical skills such as technique, depth, and visual spatiality through dissections for a better understanding of the human anatomy and the central nervous system. Thus, brain tissue preservation and coloration techniques have emerged as alternatives to standard morphological education, training and learning for neurosurgery residents. This article pretends to describe this techniques and the different cerebral vascular coloration methods. We seek to facilitate the creation of microsurgery laboratories and propose new alternatives that can be applied in the education of students and neurosurgery residents. Keywords

brain; cadaver; dissection; neuroanatomy; plastination. 


\section{Introducción}

Hay múltiples herramientas de enseñanza que han emergido con los avances tecnológicos y que han mejorado la presentación de las estructuras neuroanatómicas como un instrumento de educación (1). Las técnicas de preservación de tejidos cerebrales y coloración han surgido como una alternativa para fomentar la educación y el aprendizaje de anatomía a los estudiantes, así como una solución al problema que enfrentan muchas instituciones de educación superior, debido a la poca disponibilidad de cadáveres y a los altos costos relacionados con estos.

Un entendimiento preciso de la anatomía cerebral es fundamental en la práctica y entrenamiento de los neurocirujanos (2). El estudio anatómico de los cráneos y cabezas de cadáveres se ha vuelto uno de los métodos más útiles dentro de este campo (3), debido a que permite analizar variaciones anatómicas en las poblaciones y practicar habilidades quirúrgicas por medio de las disecciones; el mejor método para el entendimiento de la anatomía humana $(2,4)$. Para proveer el detalle anatómico con el que se encuentran los neurocirujanos en el quirófano, es imperativa la adecuada preparación de especímenes mediante el uso de técnicas de fijación de tejido y sustitución de la coloración in vivo por marcadores artificiales que permitan una diferenciación adecuada de los sistemas venoso y arterial (5). Con lo anterior se ampliaría el entrenamiento que reciben los residentes de neurocirugía y los neurocirujanos, aparte de que se impactaría positivamente en la atención brindada a los pacientes y durante las cirugías.

Pocos estudios de la literatura han profundizado en las técnicas de coloración vascular de los especímenes cadavéricos, y persisten las discrepancias en las técnicas de inyección y coloración óptimas (2). El principal objetivo de esta revisión es describir las diferentes técnicas de preservación de cerebros, así como el proceso coloración vascular cerebral y las diferentes soluciones de tinción que se han propuesto, como una alternativa de educación y practica neuroquirúrgica.

\section{Técnicas de conservación de tejido cerebral}

La descomposición es un proceso vital en la naturaleza, pero es un impedimento para los estudios morfológicos, de investigación y de enseñanza (6). Debido a esto, a lo largo del tiempo se han creado diferentes técnicas para preservar los tejidos corporales. Los principales factores que deben tenerse en cuenta en el momento de conservar el tejido cerebral son su rigidez, el tiempo de preservación y la seguridad biológica (3). A continuación, se describen las principales técnicas de preservación cerebral.

\section{Fijación por formol}

Es el método más común. Consiste en la suspensión en fijadores a base de formol a diferentes concentraciones; no obstante, resulta poco agradable debido a los olores y a la irritación ocular generada por los químicos utilizados (7). Adicionalmente, requiere un mantenimiento constante de los especímenes y la preservación del color de los tejidos es pobre. Todos estos factores y los riesgos biológicos asociados al formol (8) limitan su utilidad como técnica de enseñanza. Sin embargo, debido a los bajos costos que implica, es una de las técnicas más utilizadas en Colombia.

\section{Plastinación}

La plastinación es una técnica para preservar el cuerpo o partes de este, en la cual el agua y los lípidos se someten a una impregnación forzada de polímeros, resinas o epoxis, con lo que se obtienen especímenes anatómicos secos, duraderos, sin olor y que retienen la mayoría de las propiedades de la muestra original $(9,10,11)$. Esta técnica fue desarrollada por Gunther von Hagens, en 1977, y se ha usado de forma exitosa en todo el mundo para el estudio de la morfología humana $(12,13)$. Sin embargo, establecer un laboratorio de plastinación es costoso y muchos 
de los materiales patentados no están disponibles localmente (7).

Esta técnica incluye cuatro pasos básicos: 1) fijación, 2) deshidratación y desengrase, 3) impregnación forzada y 4) endurecimiento o curado (14). Se requieren los siguientes materiales: bomba de vacío con un regulador, congelador a $-25^{\circ} \mathrm{C}$, tubos de vacío, jarras de vidrio, bolsas plásticas de trabajo pesado, entre otros. Los materiales consumibles son los polímeros, la acetona y el formol (tabla 1).

\section{Tabla 1}

Etapas de la técnica de plastinación

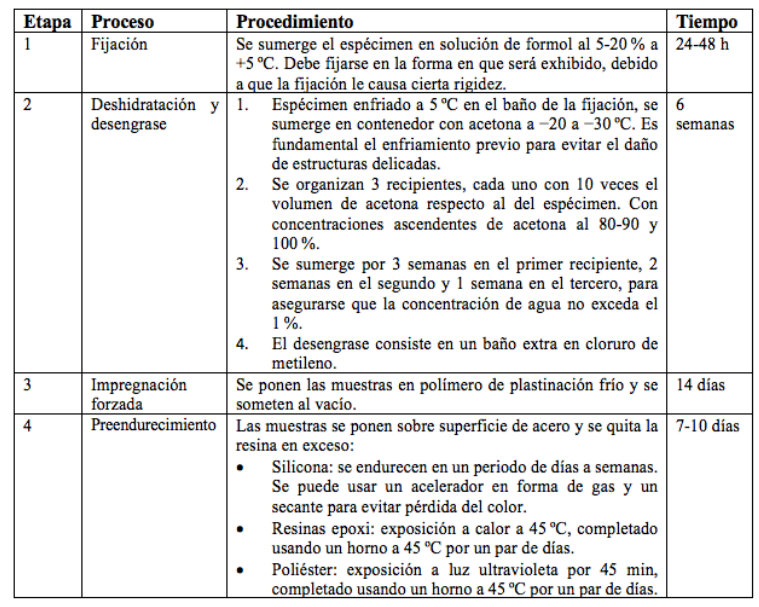

Fijación: proceso para prevenir autolisis y putrefacción. Se puede hacer con cualquier solución de formol al 5\%-20\%, y dependiendo del tamaño del espécimen puede tomar entre 24 y 48 h. De acuerdo con Bickley et al. (15), la preservación del color se favorece con solución de formol al $5 \%$ a $+5 \stackrel{\circ}{-}$. No debe hacerse en tejidos almacenados en soluciones que contienen glicerol, debido a que esto puede interferir con el proceso de curación. Si se va a colorear la vasculatura cerebral, debe ser previo a la fijación, para obtener buenos resultados (14).

Deshidratación y desengrase: la criosustitución es el método de elección para la deshidratación. Consiste en la remoción completa de los cristales de agua de los tejidos previamente fijados, por medio de la exposición seriada a soluciones de concentración creciente de acetona. La deshidratación puede hacerse con alcohol, pero su uso toma más tiempo, afecta la coloración y resulta en mayor disminución del tamaño (14). Los especímenes ricos en lípidos que serán plastinados con epoxis deben ser desengrasados para mejorar los resultados finales de la plastinación. Este proceso consiste en la disolución de los lípidos fuera de los tejidos.

Impregnación forzada: este paso se realiza en una cámara de vacío donde los especímenes saturados en acetona se sumergen en un baño de polímero líquido. Disminuye la presión y la extracción de la acetona genera un vacío adentro de los especímenes que genera la penetración del polímero. La presión debe ser regulada para evitar el daño de la muestra (14).

Endurecimiento o curación: es el último paso y varía según el tipo de polímero utilizado (14).

Según Bickley et al. (15), para lograr una mejor preservación del color se debe usar la práctica de freeze fixation, que se define como la fijación y simultánea deshidratación de los especímenes en acetona a $-25^{\circ} \mathrm{C}$. Se hace mezclando 5 partes de formalina estabilizada con metanol, con 95 partes de acetona y enfriando esta mezcla a $-25^{\circ} \mathrm{C}$ para sumergir los especímenes previamente enfriados a $5^{\circ} \mathrm{C}$. El tiempo de fijación no debe exceder dos semanas.

Hay cuatro técnicas clásicas definidas según el tipo de polímero utilizado, cada una produce especímenes con diferentes particularidades (16):

Silicona S10: opacos, flexibles, recuperan su forma original.

COR-TECH: permite controlar el grado de firmeza y flexibilidad de los especímenes de acuerdo con la mezcla de materiales.

Epoxi E12: piezas delgadas, transparentes y firmes. Se usan para segmentos de órganos o cuando se busca el estudio topográfico de estructuras.

Poliéster P35/P40: semitransparentes y firmes.

Para la plastinación del cerebro se recomienda el uso de la técnica P35/P40, debido a que permite una excelente diferenciación de la sustancia gris y blanca, y la producción de especímenes libres de olor a formol, con un acabado estéticamente agradable (17). La plastinación no tiene como único fin preservar 
tejidos, sino que puede aplicarse como un modelo de enseñanza (9). El uso de especímenes preservados por este método permite a los estudiantes correlacionarlos con imágenes radiológicas y aumentar su entendimiento (17).

\section{Diafanización}

Es un proceso que busca igualar los índices de refracción del tejido tratado y el medio en el cual se encuentra, para producir especímenes transparentes o diáfanos (18). Es un método muy flexible que permite el estudio de componentes anatómicos como centros de osificación y la vascularización (19).

Uno de los principales métodos consiste en la fijación del espécimen en una solución de formol al $10 \%$, para después deshidratarlo utilizando soluciones sobresaturadas de yodo en alcohol al $70 \%$. Posterior a este paso, se aplican las tinciones para los centros de osificación que se producen por medio de la mezcla de colorantes, glicerina e hidróxido de potasio.

El estudio de elementos vasculares a través de la diafanización precisa la repleción de los vasos de interés con diferentes materiales, teniendo en cuenta la resistencia y los índices de viscosidad de estos, así como el tamaño de los vasos (18). Se describen soluciones de coloración con tinta china filtrada con formol al $10 \%$ mezclada con resinas de poca viscosidad (20). Sin embargo, hay pocos estudios que describan el uso de esta técnica en el cerebro.

\section{Corrosión}

Se emplea para evidenciar estructuras internas de órganos, incluyendo conductos, venas, arterias y túbulos (16). Se inyectan polímeros en estado líquido en conductos corporales susceptibles de ser canalizados. Posterior a la solidificación de este material, se realiza el proceso de corrosión con bases o ácidos fuertes a altas concentraciones que reaccionan con el tejido y dan como resultado un molde de la estructura inyectada previamente.
En esta técnica existen múltiples variaciones en cuanto al material inyectado, entre estas polímeros, látex y silicona. Una de las ventajas más significativas de esta técnica es que permite una adecuada visualización de los recorridos vasculares, que abarca las extensiones capilares y los vasos de pequeño diámetro (19).

Esta técnica puede usarse a nivel microvascular, para lograr la visualización de vasos por medio del microscopio electrónico de barrido; sin embargo, esta variación del proceso de corrosión usual se emplea más en el ámbito de investigación que en la academia (21).

\section{Técnicas de tinción vascular cerebral}

A lo largo de la historia, se han descrito múltiples técnicas en las cuales se han utilizado diferentes materiales para las inyecciones de la vasculatura de cadáveres: desde caucho natural hasta resinas como la silicona y otros materiales como la gelatina y la tinta china (5). Sin embargo, todas describen procedimientos similares consistentes en los siguientes pasos:

\section{Obtención de cabezas de cadáveres}

Se recomienda el uso de cadáveres frescos (no más de $48 \mathrm{~h}$ desde la muerte) para obtener mejores resultados (3); sin embargo, en nuestro medio esto resulta difícil, debido a los trámites administrativos que implica la obtención de un cadáver. Según Limpastan et al. (22), en Tailandia enfrentan dificultades similares, por lo que proponen como solución la refrigeración de los cuerpos a $-10^{\circ} \mathrm{C}$, con el posterior descongelamiento de -2 a $-8^{\circ} \mathrm{C}$ en un periodo de 48 h (23).

Para la preparación de la cabeza, el cuello debe seccionarse con una sierra en la vértebra C5-C7, a fin de tener una adecuada exposición de los vasos cervicales y preservar la médula espinal. Hay dos factores importantes que facilitan los demás pasos: en primer lugar, se prefieren cadáveres jóvenes, debido a que hay una menor estenosis de las carótidas, entonces la inyección de la coloración es más fácil, porque hay 
menor resistencia. En segundo lugar, la sección del cuello debe hacerse tan abajo como sea posible, para tener suficiente longitud de vasos extracraneales y facilitar su canulación (2).

\section{Exposición de los grandes vasos}

El objetivo de este paso es la exposición de seis vasos en el cuello: las arterias vertebrales, las arterias carótidas comunes y las venas yugulares internas. Primero, se debe estabilizar la cabeza con la base del cuello expuesta hacia arriba, y posterior a esto se debe disecar el tejido para aislar $1,5-2 \mathrm{~cm}$ de cada vaso del tejido blando circundante $(2,5)$. Este paso toma entre 15 y 30 min en completarse.

\section{Canulación de los grandes vasos}

El objetivo es asegurar la canulación de los grandes vasos, utilizando tubos plásticos del tamaño adecuado. Sanan et al. (2) describieron que han logrado un proceso de canulación exitoso usando tubos de succión, tubos intravenosos, catéteres de ventriculostomía, tubos de tórax y tubos nasogástricos. Sin embargo, Alvernia et al. (5) refirieron mejores resultados mediante el uso de catéteres Foley de silicona cortados en un ángulo de 45ํㅡㄹ debido a que estos vienen de diferentes tamaños, tienen la rigidez adecuada y son los suficientemente flexibles como para permitir su manipulación. Además, indicaron que el balón puede usarse para ocluir el vaso y evitar que la solución de coloración se salga. En la tabla 2 se presenta el orden de canulación propuesto por Alvernia et al. (5).

\section{Tabla 2}

Orden de canulación de los grandes vasos

\begin{tabular}{|l|l|l|l|}
\hline Orden & \multicolumn{1}{|c|}{ Vaso } & $\begin{array}{c}\text { Tamaño de } \\
\text { catéter Foley }\end{array}$ & \multicolumn{1}{c|}{ Procedimiento } \\
\hline 1 & $\begin{array}{l}\text { Arterias carótidas } \\
\text { comunes }\end{array}$ & 20F-24F & Se deben insertar los catéteres 2-3 cm en el vaso. \\
\hline 2 & $\begin{array}{l}\text { Venas yugulares } \\
\text { internas }\end{array}$ & $20 \mathrm{~F}-36 \mathrm{~F}$ & $\begin{array}{l}\text { Se debe poner la punta del catéter lo más alto } \\
\text { hacia el foramen yugular que se pueda para } \\
\text { evitar la extravasación de la solución de } \\
\text { coloración previo a la entrada del } \\
\text { compartimiento intracraneal. Se sugiere poner la } \\
\text { punta en el meato auditivo externo. }\end{array}$ \\
\hline 3 & $\begin{array}{l}\text { Arterias } \\
\text { vertebrales }\end{array}$ & $12 \mathrm{~F}-18 \mathrm{~F}$ & $\begin{array}{l}\text { Deben disecarse del foramen transverso para ser } \\
\text { canuladas. }\end{array}$ \\
\hline
\end{tabular}

Los tubos se aseguran a los vasos y al tejido circundante con suturas de seda 2-0 para garantizar un cubrimiento a prueba de agua y evitar el desplazamiento accidental durante el proceso de inyección. Asimismo, se usa el catéter más grande posible.

\section{Irrigación de sistemas vasculares}

El objetivo es eliminar coágulos de sangre o residuos del fijador de formol que estén alojados en los grandes vasos, para permitir una coloración óptima de la vasculatura. Hay diversas metodologías propuestas para llevar a cabo este paso.

Sanan et al. (2) plantearon ubicar la cabeza en un lavabo y conectar una cánula a una fuente de agua por medio de tubos flexibles. Sugieren usar agua caliente e ir aumentando lentamente el flujo hasta 250-500 ml/min para la irrigación de las arterias vertebrales y hasta $1000 \mathrm{ml} / \mathrm{min}$ para los demás grandes vasos. Cada vaso se debe irrigar por separado en periodos de 15-20 min para cada vena yugular, 10-15 min para cada arteria carótida y 5-10 min para cada arteria vertebral. Aproximadamente, cada cabeza se irriga en total con 20-40 L de agua caliente de la llave. Se recomienda irrigar de nuevo al día siguiente (de forma más corta), debido a que se logran evacuar una gran cantidad de coágulos aún alojados en los vasos (2).

Por otro lado, Benet et al. (3) propusieron inyectar solución salina isotónica en vez de agua, para prevenir la aparición de edema cerebral y obtener una limpieza óptima. Se debe inyectar un vaso a la vez, hasta que el flujo que sale por el vaso contralateral esté limpio de detritos. Adicionalmente, recomendaron inyectar múltiples veces pero a presiones bajas, porque esto garantiza mejores resultados de color, textura, brillo y claridad de los especímenes.

Alvernia et al. (5) anotaron que es preferible irrigar el sistema arterial antes que el venoso, debido a que la congestión de este último puede aumentar la resistencia y disminuir el flujo arterial, que afecta la limpieza de las arterias y su dilatación efectiva. Sugieren 
la siguiente secuencia de irrigación: arterias carótidas comunes, arterias vertebrales, vena yugular interna dominante y vena yugular interna no dominante. Si se irriga de forma agresiva, habrá congestión venosa intracraneal que podrá ser evidenciada por la salida de líquido por el canal espinal; si hay un desplazamiento súbito de la médula, probablemente haya herniación del cerebro.

\section{Preparación de soluciones de coloración}

Las diferentes técnicas propuestas difieren en gran medida en este paso, debido a que se proponen múltiples fórmulas para crear soluciones de coloración. El material más usado son las siliconas; empero, hay otras propuestas que incluyen el uso de gelatinas, tinta china y látex. En la tabla 3 se presentan las fórmulas más utilizadas para la tinción de vasculatura cerebral.

\section{Tabla 3}

Soluciones de coloración vascular en orden cronológico de publicación

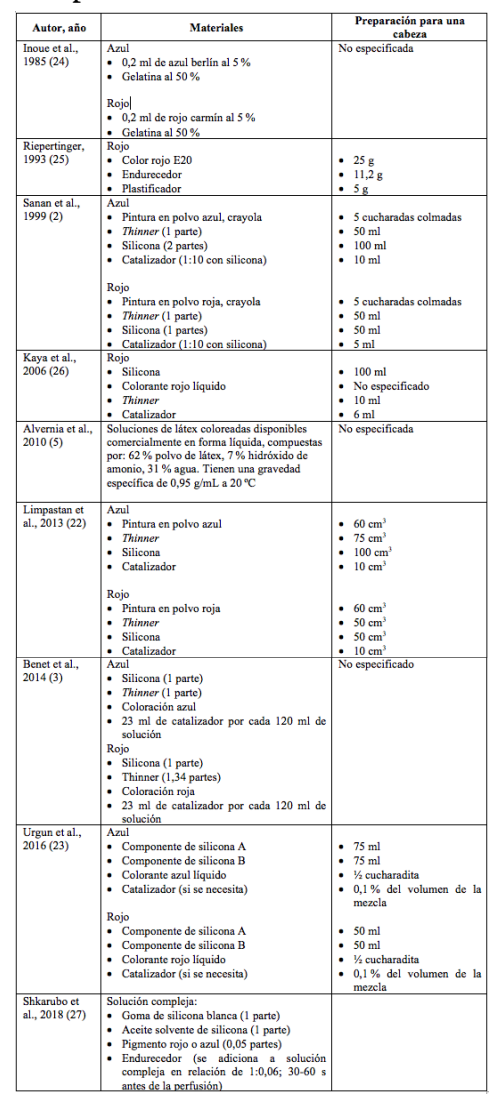

Lo ideal es preparar una mezcla con alto nivel de color, que se endurezca por sí misma. Cada cabeza requiere, en promedio, $100 \mathrm{ml}$ para el sistema arterial y $150 \mathrm{ml}$ para el sistema venoso. Es fundamental la secuencia en que se combinan los materiales: para la fórmula de Sanan et al. (2) se debe combinar la pintura en polvo con el thinner usando un recipiente con tapa y agitándolo. Después se adiciona la silicona y se mezcla hasta que el color sea uniforme. Finalmente, se adiciona el catalizador, el cual tarda entre 5 y $12 \mathrm{~h}$ para endurecerse. En muchas de las fórmulas mencionadas, la mezcla roja debe ser menos viscosa que la azul, debido a que el sistema arterial tiene más resistencia que el venoso.

\section{Fijación}

Este paso tiene como objetivo prevenir el deterioro del espécimen, conservando su distensibilidad para permitir una retracción y una maniobrabilidad quirúrgica adecuada, que simulen de la mejor forma posible las condiciones reales. Benet et al. (3) propusieron el uso de una nueva solución de embalsamiento que logró presiones de retracción 3 veces menores que las obtenidas con la técnica de conservación por suspensión en formaldehído. Esta consistía en perfundir medio litro de fijador en cada cabeza $(200 \mathrm{ml}$ en las arterias carótidas y vertebrales y $300 \mathrm{ml}$ en las venas yugulares). Después, preparaban una mezcla personalizada consistente en un $62,4 \%$ de etanol, un $17 \%$ de glicerol, un 10,2\% de fenol, un 2,3\% de formaldehído y un $8,1 \%$ de agua. Así se logra una reducción del contenido de formaldehído del 78 $\%$. Posteriormente, las cabezas eran sumergidas en una solución de la mezcla personalizada diluida en una proporción de 1:10 y almacenadas a $5^{\circ} \mathrm{C}$ por lo menos 2 días antes de la inyección del color.

El uso de esta solución mostró una mejor conservación del color respecto a los especímenes conservados por la técnica tradicional. Además, este estudio demostró que la fijación con formaldehído es un método subóptimo para 
la simulación neuroquirúrgica, porque produce mucha rigidez cerebral y dificulta la retracción. Sin embargo, este método es útil para enseñar anatomía básica y hacer disecciones de la sustancia blanca. Por otro lado, la técnica de criopreservación (sin embalsamamiento) es la que más conserva las características reales del tejido cerebral; pero su uso no puede ser mayor a $4 \mathrm{~h}$, porque estos empiezan a descomponerse y ello representa un alto riesgo biológico (3).

Otra propuesta para el proceso de fijación consiste en el uso de formaldehído al $37 \%$ en agua para lograr una fijación selectiva del parénquima, o de alcohol etílico cuando se busca preservar piel, músculos y nervios (5). Además, se debe inyectar una mezcla de formaldehído al $37 \%$ y alcohol al $10 \%$ en las arterias y venas canuladas, cerrando posteriormente los catéteres para mantener la solución por 48-72 h dentro de la vasculatura. Luego se pone la cabeza dentro de un recipiente cerrado, en una solución de formaldehído al $10 \%$ y alcohol al $10 \%$ a 4 oC por el tiempo que el espécimen permanezca en uso (5). Usando esta ténica se obtienen especímenes que pueden durar hasta 4 años en buenas condiciones.

\section{Inyección de color en sistemas arterial y venoso}

El objetivo de este paso es inyectar el árbol vascular, tanto venoso como arterial, usando la solución apropiada con pinzas vasculares para pinzar todos los vasos, exceptuando el que va a ser inyectado (2).

Sanan et al. (2) utilizaron una mezcla de silicona y la inyectaron usando una jeringa de $60 \mathrm{ml}$. Se debe aplicar con suficiente fuerza para distribuir el colorante hacia la vasculatura distal. En cierto punto durante el proceso de inyección se vuelve muy difícil inyectar más material; y aquí se debe quitar la pinza que ocluye el vaso contralateral al que se está inyectando. Continúa el proceso de inyección hasta que salga solución de coloración por el vaso contralateral, y se vuelve a pinzar este vaso y finaliza el proceso de inyección (23).
Por ejemplo, se inyecta en la arteria vertebral izquierda hasta que la resistencia sea tan fuerte que no permita continuar la inyección. En este punto, se quita la pinza de la arteria vertebral derecha y se continúa inyectando hasta que salga silicona por esta. Se debe repetir este procedimiento en cada uno de los 6 vasos. Este paso toma entre 30 y $60 \mathrm{~min}$, y puede resultar un poco desordenado, porque la solución de coloración mancha el espécimen; pero no hay necesidad de preocuparse por la apariencia externa de la cabeza y la silicona puede ser removida con facilidad una vez se endurezca $(2,23)$.

Según Benet et al. (3), se debe inyectar primero el sistema arterial para garantizar el adecuado llenado de las arterias pequeñas y distales, incluyendo las tálamo-perforantes. Recomiendan inyectar de forma bilateral las arterias carótidas comunes hasta que se evidencie la salida de color por las arterias vertebrales. Posterior a esto, se debe pinzar el sistema arterial, exceptuando una de las arterias carótidas para lograr un aumento de la presión dentro del sistema, que permita la adecuada coloración de los vasos de menor calibre. El sistema venoso debe inyectarse de la misma manera. Cuando hay cambios esporádicos en el color y la apariencia de los especímenes, se debe hidratar el tejido para que estos resuelvan.

Por otro lado, Alvernia et al. (5) sugieren inyectar primero las arterias carótidas internas usando una jeringa de $60 \mathrm{~cm}$. hasta que salga solución de látex por la carótida contralateral. Una vez esto ocurra, se debe pinzar el vaso contralateral al que se está inyectando y continuar la inyección aplicando presión de forma constante para lograr la tinción de las arterias comunicantes posteriores y el sistema vertebrobasilar. Una vez se obtenga flujo por las arterias vertebrales, se deben inyectar $10 \mathrm{ml}$ adicionales y quitar las pinzas. Este proceso debe repetirse en la arteria carótida contralateral en las arterias vertebrales.

Se debe hacer el mismo proceso en el sistema venoso, usando mayor cantidad de látex, debido a que este sistema tiene más capacitancia. También se deben inflar los balones de los catéteres para 
promover el flujo de la solución de color hacia los territorios más distales (5).

Es fundamental un proceso de irrigación adecuado; de lo contrario, permanecerán coágulos dentro de la vasculatura que aumentarán la resistencia intravascular y esto podría romper los vasos $(2,5)$. También es preciso un monitoreo constante del canal medular para verificar que no se esté aplicando una presión excesiva que hernie el cerebro. Si se desea lograr una mayor penetración de los vasos, es posible diluir la solución de coloración en agua. Para evitar la salida del colorante, se puede hacer electrocoagulación de los vasos usando fórceps bipolares (24).

\section{Extracción del cerebro inyectado}

Se debe hacer una incisión bicoronal y una craneotomía circunfleja, desde el inion hasta el opistion. Se debe preservar la dura, y hacer una disección epidural desde las convexidades laterales hasta la base del cráneo. Después, se debe retraer el cerebro suavemente y extraer del calvario por medio de cortes en las regiones clinoidea anterior y bulbar. Este proceso toma entre 20 y 30 min (26).

\section{Evaluación de los especímenes inyectados}

Es importante esperar entre 24 y $72 \mathrm{~h}$ previo a la evaluación y disección de los especímenes para un proceso de endurecimiento adecuado $(2,5)$. Se debe evaluar la calidad de los especímenes de acuerdo con la penetración del color en los capilares corticales, la consistencia de los vasos durante la disección y la presencia de extravasación de color al espacio subaracnoideo (5). Una opción para verificar que la coloración sea adecuada consiste en hacer una incisión de 1 $\mathrm{cm}$ en la piel sobre la eminencia parietal y ver la vasculatura tanto venosa como arterial de la dura (2).

\section{Almacenamiento de especímenes}

Debido al impacto negativo del formaldehído sobre la distensibilidad de los especímenes cerebrales, se recomienda el uso de etanol al $66 \%$, porque este preserva la consistencia y mantiene la coloración (23). Los especímenes almacenados de esta manera pueden preservarse en excelentes condiciones hasta durante dos años (2).

\section{Suavización de los especímenes}

Hay cierta controversia sobre la utilización de suavizantes de telas para suavizar la consistencia y disminuir la retracción de cabezas cadavéricas. Múltiples estudios han mostrado buenos resultados al usar los suavizantes sobre especímenes que han sido fijados con formol; sin embargo, estos resultados no se extrapolan a los cadáveres almacenados en alcohol etílico $(28,29)$.

Este proceso consiste en la inmersión de las cabezas en soluciones al $5 \%$ de suavizantes de telas por un periodo máximo de 5 días, debido a que si se exponen por más tiempo, se empieza a afectar la coloración de la vasculatura cerebral (2).

\section{Discusión}

El método más simple para aprender las características anatómicas humanas involucra la disección y el estudio de los cadáveres; sin embargo, la disección de especímenes no embalsamados es difícil, porque eventualmente los tejidos se descomponen y dejan de ser útiles para este fin $(2,3,5,6,7)$. Por lo anterior, surgen técnicas de preservación de tejido y coloración vascular que previenen el proceso de putrefacción y permiten la ejecución de disecciones de forma adecuada y segura, lo cual ha demostrado ser de gran utilidad para el estudio y descripción anatómica, sumado a la educación en ciencias de la salud (2). 
El formaldehído demostró ser un excelente avance en la conservación de tejidos, por sus propiedades antimicrobianas, bajo costo y fácil acceso; empero, implica riesgos para la salud y, además, causa rigidez de los tejidos. En respuesta a esto, se han encontrado una gran variedad de preservativos alternos como alcohol, fenol, polietilenglicol y fenoxietanol (30). En nuestra opinión, y de acuerdo con la literatura encontrada, el preservante más sencillo y adecuado para conservar tejido cerebral es la solución de alcohol etílico al $66 \%$, pues conserva los especímenes hasta por dos años sin afectar la coloración y la consistencia del tejido (2). Al conservar los cerebros en alcohol en lugar de formol, se preservan de mejor forma las propiedades intrínsecas del tejido y esto facilita una mejor simulación neuroquirúrgica en el momento de practicar disecciones y procedimientos.

Por otro lado, la inyección selectiva de la vasculatura cerebral la documentó en el siglo XVII Thomas Willis, quien fue el primero en describir los detalles del sistema arterial cerebral, incluyendo el polígono de Willis (31). A lo largo de los años, se han propuesto diferentes soluciones de coloración a partir de materiales como látex, silicona y tinta china. En la actualidad, hay centros de alta experiencia en disección y laboratorios de microcirugía liderados por pioneros en el área, entre ellos Albert Rhoton, Evandro Oliveira, Álvaro Campero y Cristina Martins. Durante más de 40 años, el laboratorio Rhoton ha hecho grandes aportes a la educación microanatómica que reciben los neurocirujanos y ha servido de ejemplo para la creación de muchos otros centros de disección en todo el mundo (32).

Con la inyección de tinciones mejora la calidad de detalle en los especímenes anatómicos utilizados en la educación y entrenamiento neuroquirúrgico $(33,34)$. Lo anterior es necesario para proveer el detalle anatómico con el que se encuentran los neurocirujanos al operar, especialmente teniendo en cuenta los avances modernos de técnicas microquirúrgicas, por lo cual las disecciones y los estudios neuroanatómicos — lo más cercano posible a la realidad- se convierten en nuestras "horas de vuelo" necesarias para enfrentarnos en la sala de cirugía.

No obstante, pocos estudios de la literatura profundizan en las técnicas de coloración vascular de los especímenes cadavéricos, y persisten las discrepancias en las técnicas de inyección y coloración óptimas (2). No hay ningún estudio previo a este que revise $\mathrm{y}$ conglomere las diversas soluciones de coloración propuestas a lo largo de los años. Esperamos que esta revisión facilite la creación de nuevos laboratorios de estudio anatómico y de microcirugía, para mejorar la formación de estudiantes y residentes de neurocirugía.

En un futuro, se pretende proponer una técnica que produzca especímenes de alta calidad y bajo costo; así como compararla con las otras técnicas descritas para poder determinar resultados en cuanto a conservación del espécimen, visualización vascular y costoefectividad.

\section{Limitaciones y direcciones futuras}

Se pretende llevar a cabo una revisión más extensa de las adaptaciones de las técnicas de plastinación en Colombia, ajustadas a la disponibilidad de recursos para proponer una nueva técnica que facilite la creación de laboratorios de microcirugía y nuevas alternativas educativas.

\section{Conclusiones}

El estudio anatómico en cadáveres permite estudiar las variaciones anatómicas de poblaciones y el entrenamiento de habilidades quirúrgicas en neurocirujanos y residentes de neurocirugía. Las técnicas de preservación cerebral y coloración vascular pueden ser utilizadas para producir especímenes de alta calidad y bajo costo. 


\section{Conflicto de intereses}

Los autores declaran no tener conflictos de intereses.

\section{Agradecimientos}

\section{Financiación}

Este trabajo no recibió financiación alguna.

\section{Referencias}

1. Asadi MH, Joghataei M-T, Yari A, Bahadora H, Naderian H, Azami-Tameh A. Plastination and staining of brain slices using two different dehydration methods. Anat Sci J [internet]. 2013;10(2):87-92. Disponible en: http://anatomyjournal.ir/article-1-41-e n.pdf

2. Sanan A, Aziz K, Janjua R, Loveren $\mathrm{H}$, Keller J. Colored silicone injection for use in neurosurgical dissections: anatomic technical note. Neurosurgery. 1999;45(5):1267-71. https://doi.org/10.109 7/00006123-199911000-00058

3. Benet A, Rincón-Torroella J, Lawton MT, González Sánchez J. Novel embalming solution for neurosurgical simulation in cadavers. J Neurosurg. 2014;120:1229-37.

4. Muñetón Gómez AC, Ortiz JA. Plastinación: un instrumento complementario para el desarrollo del proceso enseñanzaaprendizaje de la anatomía. Rev Med Vet (Bogotá). 2012;23:111-7. https://doi.org/10 $.19052 / \mathrm{mv} .79$

5. Alvernia J, Pradilla G, Mertens P, Tamargo R. Surgical anatomy and technique latex injection of cadaver heads: technical note. Surg Anat Tech. 2010;67:362-7.

6. Mehra S, Houdhary RC, Uli AT. Dry preservation of cadaveric hearts: an innovative trial. J Int Soc Plast. 2003;18:34-6.

7. Peralta Pineda E, Beltrán Guerra JA, Luque Bernal RM, Quijano Blanoc Y. La plastinación como técnica de preservación de material biológico para docencia e investigación en anatomía. Morfolia [internet]. 2017;9(1):55-62. Disponible en: https://revistas.unal.edu.co/index.php/ morfolia/article/view/64759/59743

8. Slater D. Health Hazards of formaldehyde. Vol. 1. London: Lancet; 1981.

9. Bhandari K, Acharya S, Srivastava AK, Kumari R, Nimmagada K. Plastination: a new model of teaching anatomy. Int J Anat Res. 2016;4(3):2626-9.

10. Pashaei S. A brief review on the history, methods and applications of plastination. Int J Morphol. 2010;28(4):1075-9.

11. Acevedo-Arroyave LM, Rojas MA, Velásquez JM. Técnica de plastinación de la Universidad de Antioquia: una adaptación del método estándar alemán. Iatreia. 2018;31(3):228-39. https://doi.org/10.1753 3/udea.iatreia.v31n3a01

12. Elnady FA. The Elnady technique: an innovative, new method for tissue preservation. ALTEX. 2016;33(3):237-42.

13. Jiménez Mejía $R$, Isaza Castro $O$. Plastinación, una técnica moderna al servicio de la anatomía. Iatreia. 2005;18(1):99-106.

14. Ravi SB, Bhat VM. Plastination: A novel, innovative teaching adjunct in oral pathology. J Oral Maxillofac Pathol. 2011;15(2):133-7.

15. Bickley HC, Conner RS, Walker AN, Jackson RL. Preservation of tissue by silicone rubber impregnation. J Int Soc Plast. 2010;40(4):30-9.

16. Venegas Cortés CA, Dalmau Barros EA, Trujillo Jurado CA, Díaz Rojas CA. La técnica de plastinación por corrosión: realidad posible. Rev Med Vet (Bogotá). 2013;25:109-17. https://doi.org/10.19052/ mv.2303

17. Cook P, Dawson B. Plastination methods used in Auckland, New Zealand. J Int Soc Plast. $1995 ; 10(1)$.

18. Rodríguez FR, Algarilla DG. Diafanización: técnica modificada por solución rojo. Actas del Primer Congreso Virtual de Ciencias Morfológicas 
[internet]. Nov 2012. Disponible en: http://morfovirtual2012.sld.cu/index.p hp/morfovirtual/2012/paper/viewFile/216/ 471

19. Rivera Díaz ML, Suárez Rodríguez CJ, Yate Valbuena A, Cruz Marroquín CE, Barahona Botache GS, Cortés Neira AX, Arias López LA. Comparación de técnicas de conservación morfológica y su posible aplicación para la enseñanza de la anatomía. Morfolia [internet]. 2014;6(3). https://revistas.unal.edu.co/ind ex.php/morfolia/article/view/48095

20. Triviño Casado A, Ramírez Sebastián JM, García Sánchez J. Método combinado de diafanización y relleno vascular para el estudio de la vascularización del globo ocular. Arch Soc Esp Oftalmol. 1980;40:979-82.

21. Scala G. microvasculature of the cerebral cortex: a vascular corrosion cast and immunocytochemical study. Microsc Res Tech. 2014 sep;263:257-63.

22. Limpastan K, Vaniyapong T, Watcharasaksilp W, Norasetthada T. Silicone injected cadaveric head for neurosurgical dissection: prepared from defrosted cadaver. Asian J Neurosurg. 2013;8(2):10-2.

23. Urgun K, Toktas ZO, Akakin A, Yilmaz B, Şahin S, Kiliç T. A very quickly prepared, colored silicone material for injecting into cerebral vasculature for anatomical dissection: a novel and suitable material for both fresh and non-fresh cadavers. Turk Neurosurg. 2016;26(4):568-73. https://doi. org/10.5137/1019-5149.JTN.12293-14.1

24. Inoue T, Kobayashi S, Sugita K. dye injection method for the demonstration of territories supplied by individual perforating arteries of the posterior communicating artery in the dog. Stroke. 1985;16(4):684-7.

25. Riepertinger A. E 20 color-injection and plastination of the brain. J Int Soc Plast. 1989;7:8-12.

26. Kaya AH, Sam B, Celik F. A quicksolidifying, coloured silicone mixture for injecting into brains for autopsy: technical report. Neurosurg Rev. 2006;29:322-6.
27. Shkarubo MA, Shkarubo AN, Dobrovolsky GF, Polev GA, Chernov I V, Andreev $\mathrm{DN}$, et al. making anatomical preparations of the human brain using colored silicone for vascular perfusion staining (technical description). World Neurosurg. 2018;112:110-6. https://doi.org/10.1016/j. wneu.2018.01.102

28. Blaney SP, Johnson B. Technique for reconstituting fixed cadaveric tissue. Anat Rec. 1989 Aug;224(4):550-1.

29. Krishnamurthy S, Powers SK. The use of fabric softener in neurosurgical prosections. Neurosurgery. 1995 Feb;36(2):420-4.

30. Macdonald GJ, MacGregor DB. Procedures for embalming cadavers for the dissecting laboratory. Proc Soc Exp Biol Med. 1997 Sep;215(4):363-5.

31. Goodrich JT. A millennium review of skull base surgery. Int Soc Pediatr Neurosurg. 2000 Nov;16(10-11):669-85.

32. Martins C. Rhoton's lab. World Neurosurg. 2016;92:623-36. https://doi.org/10.1016/j. wneu.2016.06.035

33. Latarjet $M$, Juttin $P$. Use of injections of plastic substances in anatomopathological studies of the lung. Poumon. 1952 May;8(5):459-63.

34. Latarjet M. Plastics in anatomical technique. Sem Med. 1952 Oct;28(74):10. 